\title{
An Assessment of Graphics Faculty and Student Learning Styles
}

\author{
M A. Sadowski, Ph.D. \\ School of Technology \\ Purdue University, West Lafayette, IN 47907 \\ J. A. Birchman, M.A. \\ Computer Graphics Technology \\ Purdue University, West Lafayette, IN 47907
}

\author{
L. V. Harris, Ph.D. \\ Information and Management Technology \\ Arizona State University, Mesa, AZ 85212
}

\begin{abstract}
It is generally accepted that the ability to visualize is an important tool for engineers and technologists especially in Engineering Graphics. Enhancing the spatial visualization abilities of engineering students has long been a focus of engineering graphics educators. A variety of tests and procedures to determine learning styles have been developed and used over the years. As professors, we tend to teach the way we learn, whether that is good for the students or not. Understanding our own learning style as well as the styles of our students might help us become better communicators. There are a wide variety of tests and indicators for determining learning styles. Kolb (2001), Herrmann (1995), and others have similar but different theories on learning styles. Most of us are familiar with the Myers Briggs Type Indicator tests (MBTI) given to high school students to help them make educated decisions about their career choices. A search on the web will turn up numerous sites and on-line tests. Traditionally, instructors have encouraged to present information in several different modes to engage students with a variety of learning styles.
\end{abstract}

This paper presents the results of a pilot study that examined the learning styles of graphic educators and graphics students using the Style Delineator by Anthony Gregorc (2000). The Style Delineator is a self-assessment instrument for adults and can be used as a tool for understanding learning as well as teaching styles. For the purpose of this pilot study, the student participants were limited to undergraduates majoring in computer graphics technology. The faculty participants were university graphics instructors with a variety of academic and industrial backgrounds.

\section{Introduction}

Much research has been done to assess how the human mind operates, how it perceives and processes information. These individual learning differences are referred to as "learning styles"

"Proceedings of the 2005 American Society for Engineering Education Annual Conference \& Exposition Copyright (C) 2005, American Society for Engineering Education"” 
(Butler, 1987). As a result, many learning models have been developed by which an individual's style of learning can be assessed. Educators can begin an assessment of their own teaching style and compare their findings to an assessment of their students' learning styles. Butler (1987) points out that a change in teacher attitude and action can form a "bridge" to the learner when the educator first begins to see things from the learning perspective of the student. The next step is taking action to lead the learner through the task in another way more conducive to his/her style. Several of these learning models are presented in this paper for comparison.

\section{The Gregoric Style Delineator \\ History}

As early as 1970, Anthony Gregorc (2000), a teacher, school administrator and professor of education, was working on an assessment tool as "... a means of addressing the question of how, why, and what individuals can, will, and do learn."

Gregorc's interpretation of style was based on his Mediation Ability Theory of how the mind works. He believes that each person has "natural qualities" that are expressed through mind channels. How a person uses these channels is referred to as their "mediation abilities" (Butler, p. 12). He defines four types of mediation abilities: perception, ordering, processing, and relating. His Style Delineator focuses on two of these abilities - perception and ordering.

Gregorc states, "perceptual abilities are the means through which you grasp information ... Ordering abilities are the ways in which you authoritatively arrange, systemize, reference and dispose of information"(Butler, p.13). Perceptual ability is the way in which the individual perceives the world in abstract or concrete terms. Ordering ability is the way in which the individual organizes information, whether it is sequentially or randomly.

Through extensive research interviews, Gregorc (2000) identified four channels of mediation that individuals use for perception and ordering. These "channels" serve as the "frames of reference" which influence the individual's experience and resulting behavior. The Phenomenology research method was used to classify overt behaviors (phenos) and match them with underlying causes (noumena) in order to draw conclusions about the nature (logos) of the individual's style. He stated, "Styles are symptoms of underlying psychological frames of reference and of driving mental qualities of the mind" (Butler, p.12).

As a result of his early research, The Gregorc Style Delineator was developed in 1982. The Gregorc Style Delineator is a self-analysis tool that identifies an individual's "mediation abilities" or the channels used to receive and express information. The outward appearance of one's "mediation abilities" is the individual's "style" (Gregorc, 1982).

\section{Assessment Instrument}

The Gregorc Style Delineator is used to determine a person's style by assessing two types of mediation abilities: perception and ordering. Perceptual ability is determined by two qualities: abstractness and concreteness. Whereas the qualities that control one's ordering abilities are sequence and randomness. Each mind has all four of these qualities, but we use them with different intensity. The channels defined by Gregorc (2000) couple these qualities to determine the person's "qualitative orientation to life."

\footnotetext{
"Proceedings of the 2005 American Society for Engineering Education Annual Conference \& Exposition Copyright $\left({ }_{0} 2005\right.$, American Society for Engineering Education"
} 
The Gregorc Style Delineator uses a word matrix as a basis for determining a person's style. Ten sets of words, in groups of four, are presented to the individual. The individual is asked to rank (1 low -4 high) each set of words according to how they apply to themselves. For example:

\begin{tabular}{lclc}
\multicolumn{1}{r}{ Set 1 } & \multicolumn{2}{c}{ Set 2 } \\
Word & Rank & Word & Rank \\
objective & 2 & perfectionist & 4 \\
evaluative & 3 & research & 3 \\
sensitive & 4 & colorful & 1 \\
intuitive & 1 & risk-taker & 2
\end{tabular}

After all the word sets are ranked, points are added across the rows and then down. Two row scores added together determine each style category. Once the scores are totaled, they are charted on a grid by quadrants - Concrete Sequential, Abstract Sequential, Abstract Random and Concrete Random. Any number over 27 indicates a dominant mediation channel. Once an individual understands their learning style, they can use appropriate strategies to strengthen their learning abilities. From a student's perspective, they can compensate for a difference in their learning style and the instructor's teaching style by performing other activities. From a teacher's perspective, they can try to accommodate different learning styles by offering a variety of learning activities.

\section{Teaching Styles}

Butler (1987)has created a profile of four teaching styles based on the Gregorc mind channels. Following is a summary of the four styles and how the educator in each category approaches teaching:

\section{Concrete Sequential}

The concrete/sequential learner is product-oriented, not people-oriented, and can be characterized as ordered and objective (Gregorc, 1982). They can be described as hardworking, dependable and organized. An individual strong in this category learns in an orderly, step-bystep way and prefer hands-on activities (Butler, 1987).

According to Butler (1987) concrete sequential teachers favor behavioral objectives that have measurable outcomes, and immediate and specific application for students." They organize class materials so students move through activities in a logical way and apply the knowledge gained in a practical way. Activities include informational lectures, demonstrations and self-paced instruction. Since they focus on "task-oriented achievement," they may use outlines, overheads and checklists to help student's structure content.

\section{Abstract Sequential}

The abstract/sequential learner is evaluative, logical and rational. Butler (1987) describes the abstract/sequential learner as analytic, structured and systematic. This type of learner prefers reading and analysis, lectures and discussions. 
"Abstract sequential teachers favor conceptual objectives with outcomes that indicate the student's ability to analyze, theorize and evaluate ideas" (Butler, 1987). They present ideas sequentially through lectures or readings and provide reference sources for other support materials. Activities focus on lectures, debates, reports and presentations. Students analyze, interpret and report on topics.

\section{Abstract Random}

The abstract/random learner is people-oriented, not product-oriented, and can be characterized as lively and spontaneous (Gregorc, 1982). They can be described as imaginative, perceptive and spontaneous. Individuals in this category prefer to focus on themes, ideas, feelings and activities that allow for group interaction and communication (Butler, 1987).

"Abstract random teachers write global objectives. Outcomes show the students' understanding, appreciation, and interpretation of the subject matter as well as of themselves" (Butler, 1987). Their classes provide students many ways to learn from each other through interaction and sharing. Activities include group projects, discussions and teaching/learning teams. Abstract random teachers are more concerned with the learning process then with the product produced.

\section{Concrete Random}

The concrete/random learner is perceptive and likes to experiment and take risks (Gregorc, 1982). They can be described as curious, creative, and adventurous. As learners, they prefer experimentation and problem-solving approaches to learning and like activities which encourage active investigations and applications (Butler, 1987).

"Concrete random teachers favor global objectives that encourage students to raise questions, delineate problems, generate alternatives, and propose solutions" (Butler, 1987). They do not limit learning to the classroom and may contain unusual resources such as discarded appliances or art supplies that students can use to explore or be creative. Activities include independent study projects, experiments, case studies or discussions. Students like to look at broad applications, so activities such as brainstorming and creative problem solving are encouraged.

\section{The Testing Group \\ The Sampling}

This study compared a group of graphics faculty with a group of graphics students. The faculty group was composed of 56 faculty members who attended the EDGD MidYear Meeting in Williamsburg, Virginia in November 2004 and 15 Computer Graphics faculty members from Purdue University. The student population was composed of 90 first semester freshmen majoring in Computer Graphics Technology in the College of Technology at Purdue University.

There was a ratio of 68:22 male:female student participants in the study for a total of 90, and a ratio of 58:13 male:female faculty in the study for a total of 71 . One-fourth ( 25 percent) of the student population was female while 18 percent of the faculty population was female. The convenient sampling had a similar ratio of male to females in both the student and faculty populations.

"Proceedings of the 2005 American Society for Engineering Education Annual Conference \& Exposition Copyright (C) 2005, American Society for Engineering Education", 
Figure 1.

The Freshmen Students Overall According to the 2004 study, 51 percent of the Purdue freshmen computer graphics students sampled were found to be concrete random learners (Figure 1). The findings further indicated that the college freshmen were least likely to be abstract sequential learners ( 24 percent). There were an equal number of learners who were concrete sequential learners (34 percent) and abstract random learners (34 percent).

\section{FACULTY AND STUDENT POPULATIONS}

Seventy-one faculty participated in the study, while 90 freshmen students were participants.

FACULTY

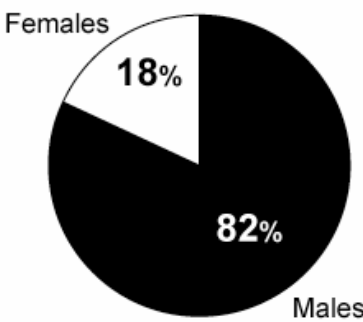

STUDENTS

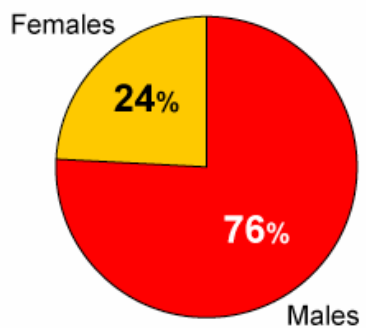

Source: 2004 Study

Figure 2.

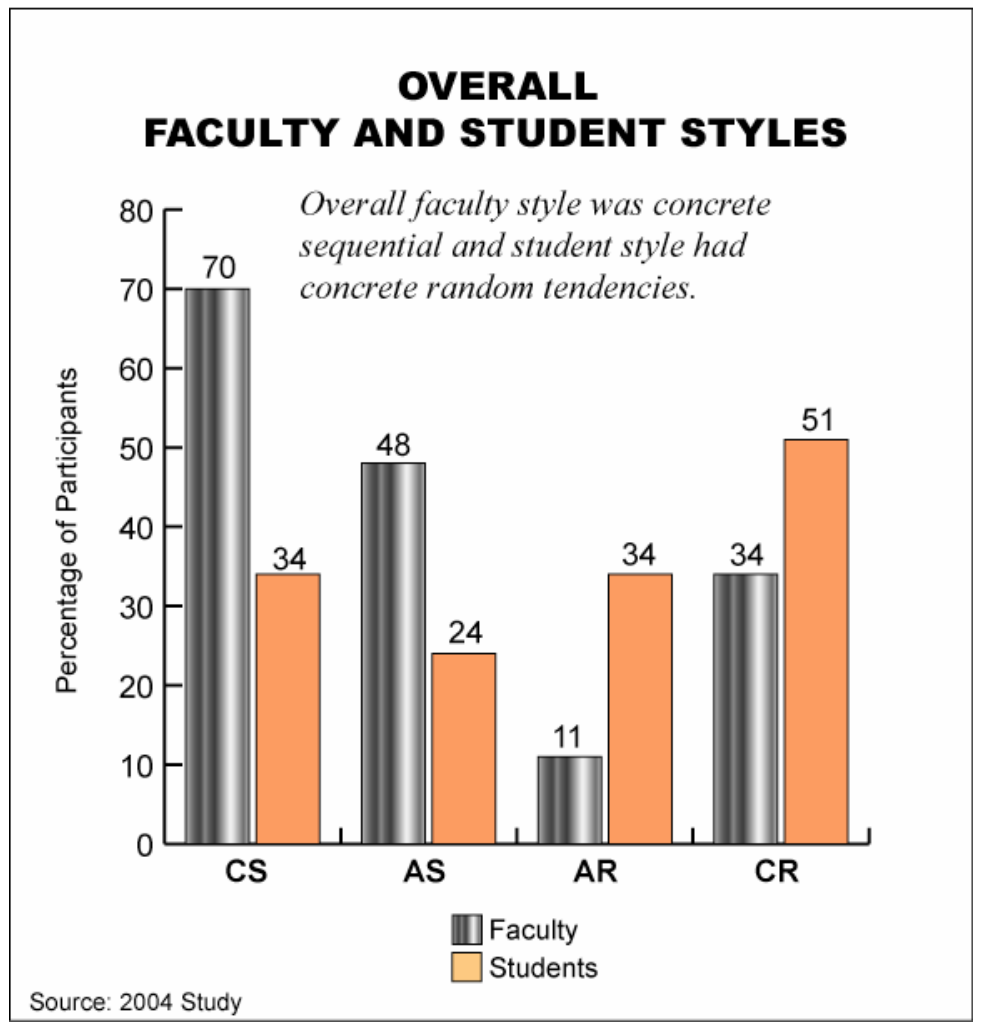

\section{The Faculty Overall}

According to the 2004 study, 70 percent of the faculty sampled was found to be concrete sequential learners (Figure 2). The findings further indicated that the computer graphic faculty was least likely to be abstract random learners (11 percent). Concrete random learners (34 percent) and abstract sequential learners (48 percent) completed the remainder of the total.

\section{The Freshmen Students By Gender} According to the 2004 study, half of the male students and half of the female students were found to be concrete random learners. Male and female students were similar in learning style preferences with both indicating abstract sequential as the least used mind style (See Figure 3). 


\section{The Faculty By Gender}

If the faculty data by gender is dissected, an interesting finding emerges. More male faculty were found to be concrete sequential learners than any of the other mind styles, whereas more female faculty were found to be concrete random learners (See Figure 4). Both genders were least likely to be abstract random learners.

Figure 3.

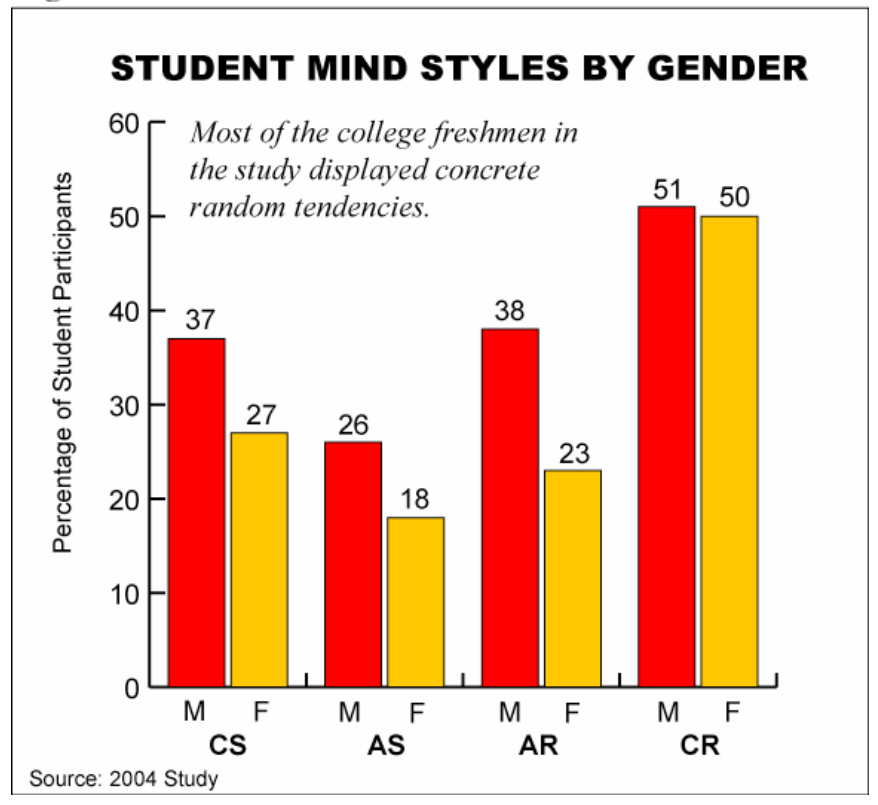

Figure 4.

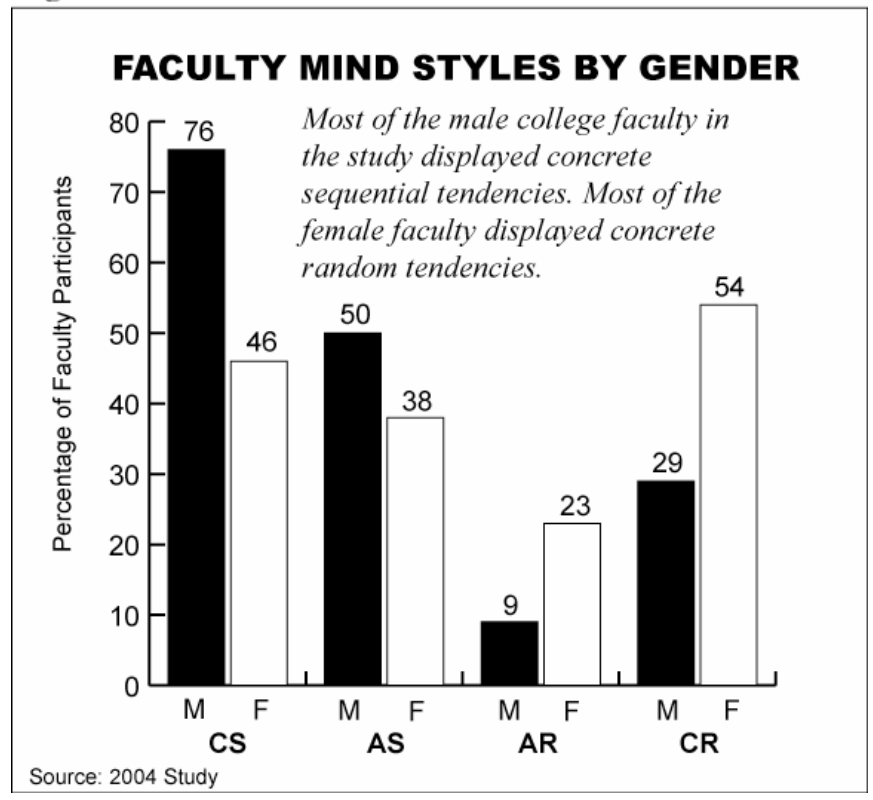

Comparing the Mind Styles of Students and Faculty

Male and female students were found to be similar to each other in learning style preferences.

Male and female faculty were found to have more differences in their mind styles when compared to each other. Female faculty members in this study were found to have the same learning style as the majority of the freshmen students, so if they teach the way they learn, learning should take place.

Male faculty were found to be similar to the female faculty and sampled students in perceptual quality. They differed, however, in the ordering style they preferred.

More student and faculty participants in the study were concrete learners. As concrete learners, they perceive the world using their five senses of sight, hearing, touch, smell, and taste. The saying "It is what it is," is the mantra of this group of learners. The concrete perception of the world is one that does not look for hidden agendas or analyze the abstract relationships between ideas. Those strong in the concrete have a tendency to be direct and literal communicators. 
Figure 5 .

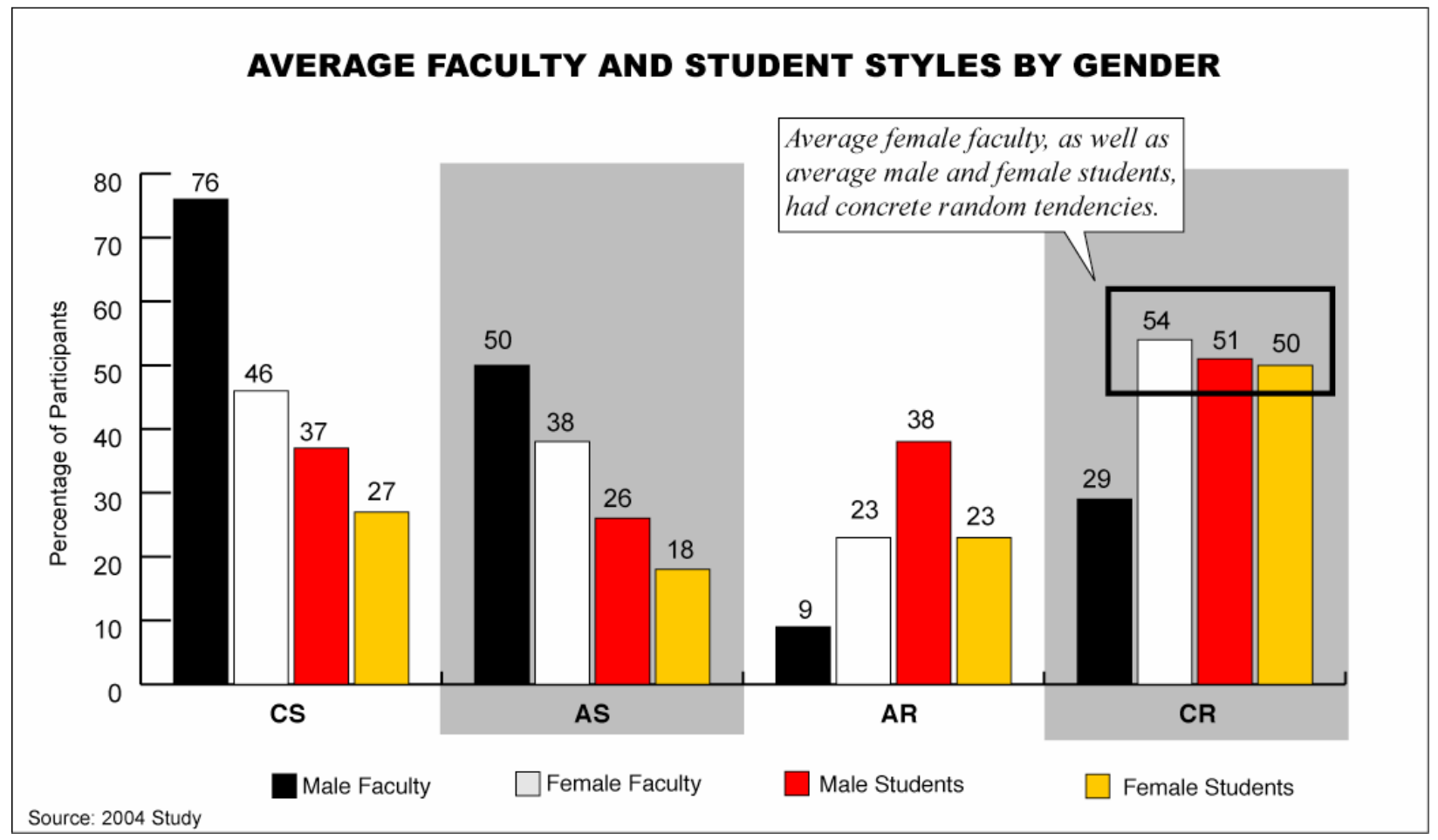

Because the difference between the participants in this study was in the preferred ordering style, this is the area that should be focused on. More student participants and female faculty preferred random ordering, and tend to organize information in "chunks" and in no particular order. Information is ordered in three-dimensional patterns; in other words, events are linear, but can be affected by external variables. Often steps are skipped in a procedure, but still resulting in the same conclusion. Sometimes random learners begin at the end of the process and work backward. Sometimes they begin in the middle. They have a tendency to be more impulsive and less planned.

More male faculty in the study preferred a sequential ordering style. This is a logical and traditional approach to organizing information. A plan is the blueprint of the process. Because they tend to organize information in a linear fashion - step-by-step, the ordering style of the female faculty and the students who are random learners, appears haphazard to them.

As concrete sequential learners, the male professors preferred not to change their plan and ordered objective. Because they are not people-oriented, they focus on the outcome rather than the process, and therefore are product-oriented.

Because the majority of the female professors and the majority of the student sample population shared similar learning styles as concrete random learners, they preferred problem solving approaches and active investigation and experimentation. The focus for concrete random learners is on process, methodology, and application, and a preference in engaging and competitive environments. Because they like to take risks, they are unique and inventive learners.

\section{Conclusion}

"Proceedings of the 2005 American Society for Engineering Education Annual Conference \& Exposition Copyright (C) 2005, American Society for Engineering Education”, 
Learning styles assessment is a valuable tool for students and faculty to use because it allows them to think deeply about what their preferences are, what their dominant mode of thinking is, and how they view the world. As faculty we can adjust both the way we teach and types of activities we offer our students. This study was limited to one group of students and one group of faculty. More data needs to be collected before we can reach definite conclusions about the differences and similarities between faculty and students and between males and females; however, the data presented in this paper provides insight into the different styles of this small sample.

\section{References}

Butler, K. A. (1987). Learning and teaching style: In theory and practice $\left(2^{\text {nd }}\right.$ Ed). Connecticut: The Learner's Dimension.

Gregorc, A. (1982). Gregorc style delineator: development, technical and administration manual. Connecticut: Gregorc Associates, Inc.

Gregorc, A. (2000). An adult's guide to style. Connecticut: Gregorc Associates, Inc.

Herrmann, N. (1995). The creative brain: Insights into creativity, communication, management, education, and self-understanding. The Ned Herrmann Group.

Kolb, D. A. (2004). David A. Kolb on experimental learning. Retrieved October 2, 2004 from http://.infed.org/biblio/b-explrn.htm

Thinkquest.org(2000). Gregorc Learning Styles. Retrieved October 2004, from library.thinkquest.org

\section{MARY A. SADOWSKI, PhD}

As Associate Dean, Dr. Sadowski provides leadership for the Purdue University School of Technology's strategic initiatives in undergraduate education; serves as coordinator of accrediting activities and initiatives, scholarships, and enrollment management; and provides leadership for activities related to student services. Dr. Sadowski has taught a variety of courses including CAD, Web Design, Animation, and Creative Thinking. Her research interests include enhancing visualization skills and creative thinking. She has been actively involved in ASEE and the Engineering Design Graphics Division and has served the division as Vice-Chair, Chair and Editor of the Engineering Design Graphics Journal.

\section{JUDITH A. BIRCHMAN, MA}

Judy Birchman is an Associate Professor in the Department of Computer Graphics Technology at Purdue University. She received her Bachelor of Science and Master of Arts Degrees from Purdue University. A member of the Graphics Department since 1974, she has taught courses in engineering graphics fundamentals, drawing systems, $\mathrm{CAD}$, electronic publishing and multimedia. Professional activities include presentations, papers and workshops on design, graphics and multimedia topics. Professor Birchman served as the Technical Editor and the Editor of the Engineering Design Graphics Journal. As a member of the Engineering Design Graphics Division, she has held two elected positions on the executive board serving as Director of Publications and as Chair of the division.

\section{LA VERNE ABE HARRIS, Ph.D.}

Dr. La Verne Abe Harris is an Assistant Professor of Graphic Information Technology at Arizona State University. She received her $\mathrm{PhD}$ from the University of Arizona in higher education with an emphasis in technology and media arts. As a tenure-track professor, Dr. Harris has been published in several peer-reviewed journals. Her research centers on visual and technological literacy, sociotechnology, and the adoption of new technologies. Dr. Harris serves as the chair of the ASU Commission on the Status of Women for the polytechnic-focused campus, CSW Executive Board member for the University, and National Association of Industrial Technology (NAIT) Region 5 Board of Certification Member. She is also a Certified Senior Industrial Technologist (CSIT). She is a member of ASEE, EDGD, ASEE Engineering Technology Division, International Graphic Arts Education Association (IGAEA), International Technology Education (ITE), NAIT, and Epsilon Pi Tau, a technology honor society.

"Proceedings of the 2005 American Society for Engineering Education Annual Conference \& Exposition Copyright (C) 2005, American Society for Engineering Education” 